\title{
Perceived Competency, Frequency, Training Needs in Physical Assessment among Registered Nurses
}

\author{
Oh, Heeyoung ${ }^{1} \cdot$ Lee, Jiyeon ${ }^{1} \cdot$ Kim, Eun Kyung ${ }^{2}$ \\ ${ }^{1}$ College of Nursing, Eulji University, Daejeon \\ ${ }^{2}$ Department of Nursing, Chungbuk Naional University, Chungju, Korea
}

\begin{abstract}
Purpose: The purpose of this study was to identify registered nurses learning needs about physical assessment. Specifically, what are the perceived competency, frequency of skill use and the unmet training needs. Methods: The study was an exploratory survey study. The sample was 104 registered nurses. Data were collected through three instruments: The Perceived Competency in Physical Assessment Scale, the Frequency of Physical Assessment Scale, and the Training Needs of Physical Assessment Scale which incorporated 30 core Physical Assessment skills. Descriptive statistics, t-test, and Pearson's correlation coefficient were used to analyze the data. Results: Auscultation of heart and lung sounds and inspection of the spine were rated by the subjects as physical assessment skills they feel least competent and also were less frequently performed. The most competent area for physical assessment was neurological system. The respiratory and abdominal system was identified as two systems that more education would be needed. Nurses with less than one year of working experience reported needing more training. Nurses with more than five years of clinical work experience performed physical assessment more frequently than nurses with less than five year of work experience. The perceived competency was positively related to the frequency of physical assessment. Conclusion: Continuing education is necessary to further train registered nurses regarding physical assessment skills and the program needs to be focused on the area which nurses are less competent for and have high training need.
\end{abstract}

Key Words: Competency, Physical assessment, Nurses, Training needs

\section{INTRODUCTION}

Competency is defined as a level of performance demonstrating the effective application of knowledge, skill and judgment (International Council of Nurses, 2003). Clinical competency means knowledge-based, cognitive, and psychomotor skill set essential in the provision of safe, quality patient care (Gilje, Klose, \& Birger, 2007). A set of core competencies was proposed by the Institute of Medicine (IOM) in an effort to assure the quality of care and patient safety (IOM, 2003). Physical assessment either comprehensive or focused is the part of essential components of core competencies (AACN, 2008).
Physical assessment is the most frequently performed essential nursing skill set which newly graduated nurses are required to be prepared for (Kim, 2006). Physical assessment provides objective data for nursing process which leads to identify nursing problems, set goals of care, and implement nursing interventions. Physical assessment allows early recognition of deterioration through monitoring of patients' status (Minick, 1995; Minick \& Harvey, 2003). Furthermore, physical assessment helps identify illness experience of by providing ways to interact with patients (Zambas, 2010). Strong emphasis has been placed on educational preparation about physical assessment and assessment courses have become fundamentals in nursing programs (Giddens \& Eddy, 2009;

\footnotetext{
Corresponding author: Lee, Jiyeon

CEulji University, College of Nursing, 77 Gyeryong-ro 771 bun-gil, Jung-gu, Daejeon 301-746, Korea.

Tel: +82-42-259-1712, Fax: +82-42-259-1709, E-mail: Jiyeon.Lee@eulji.ac.kr
} 
Oh, Kim, Shin, \& Jung, 2004). Nurses are asked to be clinically competent in physical assessment in the era of rapid changes in health care systems with increasing acuity of patients requiring complex types of care.

Even with strong emphasis on the values of physical assessment as a part of core competencies and educational efforts in preparing and training nurses, clinical competencies about physical assessment among registered nurses seem to be insufficient. Previous studies reported that registered nurses in the United States routinely perform 30 physical assessment skills whereas advanced practice nurses in Korea mostly administer 14 inspection skills (Shin, Kim, \& Kang, 2009). It is not clear whether the differences in frequency and types of physical assessment skills performed were derived from different practice pattern, clinical practice setting, or educational preparation. To increase competency in physical assessment among Korean registered nurses it is necessary to evaluate the level of perceived clinical competency in physical assessment, additional training needs and the relationship between perceived clinical competency and the frequency of performing physical assessment among registered nurses.

\section{Purpose}

The purposes of this study were

- To evaluate the perceived competency, frequency, and training needs about physical assessment among registered nurses.

- To examine the level of perceived competency, frequency, and the training needs about physical assessment by body systems and assessment methods.

- To compare the perceived level of competency, frequency, and the training needs about physical assessment by demographic characteristics.

- To examine the relationship among competency, frequency, and the training needs about physical assessment.

\section{METHODS}

\section{Design}

This is a cross-sectional exploratory survey study.

\section{Setting and Samples}

The sample of this study consisted of registered nurses who agreed to participate in the study. Subjects were re- cruited from general and special units in one University hospital and one general hospital located in S and D city in Korea. Sample size was estimated using G*Power analysis 3.1 (Faul, Erdfelder, Lang, \& Buchner, 2007) as a function of power level of .80 , significance level of .05 , and moderate effect size of .30. From the sample estimation of 102, a total of 104 registered nurses were recruited for this study.

\section{Measurements}

Three instruments, the Perceived Competency in Physical Assessment Scale, the Frequency of Physical Assessment Scale, and the Training Needs of Physical Assessment Scale, were developed for this study by the researcher. After a literature review, a set of 30 most frequently performed 'core physical examination techniques' identified by Giddens (2007) were selected to generate preliminary items of the three instruments. Content validity index of three instruments were evaluated by clinical experts. Each item was assessed for relevance on a score of 1 4 (1=not relevant, $2=$ somewhat relevant, $3=$ quite relevant, and $4=$ very relevant). Also the reviewers were asked to assess the items in relation to the objectives and to provide critique of the instrument. Content validity index-item (CVI-I) scores ranged from .83 1.00 and the content validity index-scale (CVI-S) of three instruments found to be same as .98 . Therefore all preliminary 30 core physical examination techniques were included as content-validated items in three instruments. Reliability of the instruments was examined using internal consistency and test-retest reliability. Cronbach's alpha coefficient was analyzed using SPSS reliability analysis for each scale and test-retest reliability was conducted in two weeks interval with a subsample of subjects.

\section{1) Perceived Competency in Physical Assessment Scale (PCPAS)}

It allows participants to rate their perceived level of competency in each physical assessment item with the numeric rating scale (NRS) of 1 to 4 ( $1=$ not at all competent, $2=$ little competent, $3=$ somewhat competent, $4=\mathrm{com}-$ petent). The total competency score range from 30 120 with higher total score suggesting being more competent. The Cronbach's alpha and test-retest reliability of the Perceived Competency in Physical Assessment Scale were .94 and .77 respectively.

\section{2) Frequency of Physical Assessment Scale (FPAS)}

The FPPAS ask participants to indicate frequency of 
their physical assessment performance using the NRS of 1 to $5(1=$ very rarely; once or twice per year, $2=$ rarely; once or twice per 6 month, $3=$ occasionally; once or twice per month; $4=$ frequently; once or twice per week, $5=$ very frequently; perform the assessment on every duty). The total FPPAS score range from 30 150 with higher total score suggesting more frequent performance. The Cronbach's alpha and test-retest reliability of the Frequency of Physical Assessment Scale were .94 and .87 respectively.

\section{3) Training Needs of Physical Assessment Scale (TNPAS)}

The TNPAS measure the training needs for physical assessment with the NRS of 1 to 4 ( $1=$ not at all, $2=$ not much, $3=$ somewhat, $4=$ very). The total training needs score range from 30 120 with higher total score suggesting more training needs. The Cronbach's alpha and test-retest reliability of the Training Needs of Physical Assessment Scale were .97 and .82 respectively.

\section{Procedure}

The study was reviewed and approved by the $\mathrm{E}$ University Institutional Review Board. The chief in nursing department of two hospitals were contacted by the researcher. The purpose, procedure and implications of this study were explained to obtain the permission. Prior to data collection subjects were informed about the study and that their participation was voluntary and assured of anonymity. Written consents were obtained from the participants. Data were collected in January, 2008.

\section{Analysis}

Statistical software IBM SPSS statistics 19.0 was used to analyze the data. Descriptive statistics were used to investigate the level of perceived competency, frequency, and the training needs of physical assessment. T-test was used to compare the mean difference in perceived competency, frequency, and the training needs of physical assessment according to the characteristics of participants. Pearson correlation analysis examined the relationships among these variables.

\section{RESULTS}

\section{Demographic characteristics}

The age ranged from $22 \sim 42$ with the mean age of 26.69 \pm 3.87 . All were female. Majority of subjects graduated from diploma programs (81.7\%) and 16\% of subjects had baccalaureate degree. Most of the subjects were staff nurses (94.2\%) working in general unit including internal medicine (33.6\%) and surgical unit (52.0\%). About 18\%, $62 \%$ had less than 1 year and 5 years of work experience respectively (Table 1 ).

Table 1. Demographic Characteristics

$(N=104)$

\begin{tabular}{llc}
\hline Characteristics & Variables & $\mathrm{n}(\%)$ or $\mathrm{M} \pm \mathrm{SD}$ \\
\hline Age (year) & & $26.69 \pm 3.87$ \\
Gender & Female & $104(100.0)$ \\
Education & 3 year diploma & $85(81.7)$ \\
& 4 year baccalaureate & $19(18.3)$ \\
Practice setting & University hospital & $70(67.3)$ \\
& General hospital & $34(32.7)$ \\
Practice unit & Medical unit & $35(33.6)$ \\
& Surgical unit & $54(52.0)$ \\
& Intensive care & $10(9.6)$ \\
& Emergency & $5(4.8)$ \\
Work experience & $<1$ & $19(18.3)$ \\
(year) & $1 \sim<3$ & $27(26.0)$ \\
& $3 \sim<5$ & $18(17.3)$ \\
& $\geq 5$ & $40(38.5)$ \\
\hline
\end{tabular}

\section{Perceived competency, frequency, and training needs about physical assessment}

Mean perceived competency score was $3.09 \pm 0.34$ in the NRS of 1 to 4 meaning 'somewhat competent'. Among 30 core health assessment skills, "palpate distal pulses for circulation' was rated as the most competent skill (3.64 $\pm 0.52)$. 'Auscultate heart sounds' (2.34 \pm 0.84$)$, 'Inspect the spine' ( $2.41 \pm 0.75)$, and 'Auscultate lung sounds' (2.46 \pm 0.72 ) were rated as three least competent skills.

Mean frequency of physical assessment score was 3.61 \pm 0.64 in NRS of 1 to 5 . The 'evaluate breathing effort' was rated as the most frequently implemented skill

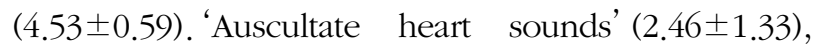
'Inspect the spine' $(2.56 \pm 1.09)$, 'Auscultate lung sounds' $(2.87 \pm 1.08)$, and 'Inspect chest shape' $(2.97 \pm 1.10)$ were rated as less frequently performed skills in the range of 'rarely performed' to 'perform sometimes.'

Mean training needs score was 3.16 \pm 0.64 in NRS of 1 to 4. Participants expressed their needs for training for all 30 skills. 'Auscultate lung sounds' (3.55 \pm 0.64$)$, 'Auscultate heart sounds' ( $3.53 \pm 0.70$ ), and 'Auscultate abdomen for bowel sounds' $(3.44 \pm 0.67)$ were rated as high for further training (Table 2). 
Table 2. Perceived Competency, Frequency, and Training needs of Physical Assessment

$(N=104)$

\begin{tabular}{|c|c|c|c|c|c|c|}
\hline \multirow{2}{*}{ Assessment skill } & \multicolumn{2}{|c|}{ Perceived competency } & \multicolumn{2}{|c|}{ Frequency } & \multicolumn{2}{|c|}{ Training needs } \\
\hline & $\mathrm{M} \pm \mathrm{SD}$ & $\operatorname{Rank}^{\dagger}$ & $\mathrm{M} \pm \mathrm{SD}$ & $\operatorname{Rank}^{\dagger}$ & $\mathrm{M} \pm \mathrm{SD}$ & $\operatorname{Rank}^{\dagger}$ \\
\hline 1. Inspect overall skin colors & $3.41 \pm 0.60$ & & $3.97 \pm 0.90$ & & $3.15 \pm 0.77$ & \\
\hline 2. Evaluate breathing effort & $3.35 \pm 0.65$ & & $4.53 \pm 0.59$ & 1 & $3.39 \pm 0.73$ & 4 \\
\hline 3. Assess mental status and level of consciousness & $3.45 \pm 0.68$ & 5 & $4.38 \pm 0.86$ & 2 & $3.29 \pm 0.83$ & \\
\hline 4. Inspect and palpate extremities for edema & $3.42 \pm 0.57$ & & $4.21 \pm 0.75$ & 4 & $3.20 \pm 0.83$ & \\
\hline 5. Palpate extremities for temperature & $3.51 \pm 0.61$ & & $4.30 \pm 0.95$ & 3 & $2.97 \pm 0.91$ & 26 \\
\hline 6. Palpate and inspect capillary refill & $2.90 \pm 0.86$ & & $3.13 \pm 1.20$ & & $3.10 \pm 0.84$ & \\
\hline 7. Palpate distal pulses for circulation & $3.64 \pm 0.52$ & 1 & $4.04 \pm 1.04$ & & $3.15 \pm 0.91$ & \\
\hline 8. Inspect wounds & $3.31 \pm 0.68$ & & $4.06 \pm 0.91$ & & $3.19 \pm 0.97$ & \\
\hline 9. Auscultate lung sounds & $2.46 \pm 0.72$ & 28 & $2.87 \pm 1.08$ & 28 & $3.55 \pm 0.64$ & 1 \\
\hline 10. Auscultate abdomen for bowel sounds & $2.83 \pm 0.67$ & & $3.12 \pm 1.15$ & & $3.44 \pm 0.67$ & 3 \\
\hline 11. Inspect abdomen & $2.83 \pm 0.63$ & 26 & $3.56 \pm 1.04$ & & $3.28 \pm 0.77$ & \\
\hline 12. Auscultate heart sounds & $2.34 \pm 0.84$ & 30 & $2.46 \pm 1.33$ & 30 & $3.53 \pm 0.70$ & 2 \\
\hline 13. Inspect skin lesions & $2.99 \pm 0.62$ & & $3.88 \pm 0.99$ & & $3.19 \pm 0.88$ & \\
\hline 14. Inspect extremities for skin color and hair growth & $2.92 \pm 0.69$ & & $3.28 \pm 1.22$ & & $2.97 \pm 0.92$ & 27 \\
\hline 15. Inspect external eyes & $2.89 \pm 0.79$ & & $3.07 \pm 1.24$ & & $3.06 \pm 0.91$ & \\
\hline 16. Evaluate speech & $3.47 \pm 0.65$ & 3 & $4.21 \pm 0.96$ & 5 & $2.93 \pm 0.92$ & 29 \\
\hline 17. Palpate abdomen for tenderness and distension & $2.99 \pm 0.65$ & & $3.90 \pm 0.93$ & & $3.30 \pm 0.81$ & 5 \\
\hline 18. Observe range of motion of joints & $2.90 \pm 0.72$ & & $3.22 \pm 1.41$ & & $3.08 \pm 0.90$ & \\
\hline 19. Inspect chest shape & $2.66 \pm 0.76$ & 27 & $2.97 \pm 1.10$ & 27 & $3.25 \pm 0.73$ & \\
\hline 20. Evaluate face for movement and sensation & $3.04 \pm 0.65$ & & $3.67 \pm 1.07$ & & $3.05 \pm 0.83$ & \\
\hline 21. Palpate extremities for tenderness & $3.07 \pm 0.70$ & & $3.54 \pm 1.08$ & & $3.02 \pm 0.91$ & \\
\hline 22. Assess muscle strength & $3.35 \pm 0.66$ & & $4.11 \pm 0.93$ & & $3.27 \pm 0.84$ & \\
\hline 23. Inspect muscles and extremities for size and symmetry & $3.15 \pm 0.71$ & & $3.39 \pm 1.23$ & & $2.94 \pm 0.86$ & 28 \\
\hline 24. Assess hearing on the basis of conversation & $3.22 \pm 0.76$ & & $3.61 \pm 1.19$ & & $2.84 \pm 0.85$ & 30 \\
\hline 25. Inspect and examine stool & $3.21 \pm 0.66$ & & $3.63 \pm 1.02$ & & $3.09 \pm 0.80$ & \\
\hline 26. Assess gait & $3.15 \pm 0.73$ & & $3.41 \pm 1.46$ & & $3.07 \pm 0.87$ & \\
\hline 27. Assess for PERRLA & $3.42 \pm 0.73$ & & $4.00 \pm 1.09$ & & $3.09 \pm 0.91$ & \\
\hline 28. Assess using Glasgow Coma Scale & $3.47 \pm 0.64$ & 4 & $4.20 \pm 0.92$ & & $3.22 \pm 0.94$ & \\
\hline 29. Inspect the oral cavity & $2.86 \pm 0.84$ & & $3.03 \pm 1.16$ & 26 & $3.02 \pm 0.84$ & \\
\hline 30. Inspect the spine & $2.41 \pm 0.75$ & 29 & $2.56 \pm 1.09$ & 29 & $3.11 \pm 0.84$ & \\
\hline Total & $3.09 \pm 0.34$ & & $3.61 \pm 0.64$ & & $3.16 \pm 0.64$ & \\
\hline
\end{tabular}

Note. PERRLA=Pupils equal, round, reactive to light and accommodation.

${ }^{\dagger}$ Top and bottom 5 ranks were marked.

\section{Perceived competency, frequency, and training needs about physical assessment by body systems and assessment methods.}

The most competent area for assessment was neurological system (3.39 \pm 0.47$)$ followed by skin system $(3.21$ $\pm 0.48)$. The least competent area was respiratory system $(2.82 \pm 0.57)$. The most frequently assessed area was neurological system $(4.05 \pm 0.60)$ followed by skin system $(3.88 \pm 0.75)$ whereas the least frequently assessed one was muscular and skeletal system (3.18 \pm 0.91$)$. Training needs were high for respiratory $(3.40 \pm 0.59)$ and abdominal 
system (3.28 \pm 0.66 ), whereas HEENT (head, eyes, ears, nose, and throat) system $(2.99 \pm 0.74)$ was rated as the lowest for further training (Table 3 ).

The items were categorized into the 4 assessment methods; 1) inspection, 2) auscultation, 3) palpation, and 4) multi-methods. Assessment skills such as 'assess mental status and level of consciousness', 'evaluate speech', and 'assess gait, which required more than one assessment skill were categorized into multi-methods. Auscultation was the least competent $(2.54 \pm 0.61)$, least frequently performed skill $(2.81 \pm 0.98)$ with the most needs for further training (3.51 \pm 0.62$)$. Multi-methods was the most competent skill (3.28 \pm 0.44$)$ with the least needs for further training.

Table 3. Perceived competency, Frequency, and Training needs of Physical Assessment by Body Systems $\quad(N=104)$

\begin{tabular}{|c|c|c|c|}
\hline Body systems & $\begin{array}{c}\text { Perceived } \\
\text { competency }\end{array}$ & Frequency & $\begin{array}{c}\text { Training } \\
\text { needs }\end{array}$ \\
\hline & $\mathrm{M} \pm \mathrm{SD}$ & $\mathrm{M} \pm \mathrm{SD}$ & $\mathrm{M} \pm \mathrm{SD}$ \\
\hline Skin & $3.21 \pm 0.48$ & $3.88 \pm 0.75$ & $3.14 \pm 0.73$ \\
\hline HEENT & $3.00 \pm 0.55$ & $3.34 \pm 0.91$ & $2.99 \pm 0.74$ \\
\hline Respiratory & $2.82 \pm 0.57$ & $3.46 \pm 0.71$ & $3.40 \pm 0.59$ \\
\hline Cardiovascular & $3.10 \pm 0.45$ & $3.48 \pm 0.87$ & $3.19 \pm 0.69$ \\
\hline Abdominal & $2.96 \pm 0.47$ & $3.55 \pm 0.81$ & $3.28 \pm 0.66$ \\
\hline Muscular & $2.88 \pm 0.57$ & $3.18 \pm 0.91$ & $3.04 \pm 0.78$ \\
\hline Neurological & $3.39 \pm 0.47$ & $4.05 \pm 0.60$ & $3.14 \pm 0.77$ \\
\hline
\end{tabular}

HEENT=head, eyes, ears, nose, and throat.

\section{Comparison of perceived competency, frequ- ency, and training needs about physical as- sessment by the demographic characteristics}

Educational preparation of nurses ( 3 vs. 4 year) did not make any difference in perceived competency, frequency, or training needs. In terms of working experience, the nurses with less than 1 year of working experience had significantly more training needs $(\mathrm{t}=2.01, p=.047)$, but the mean scores of perceived competency $(\mathrm{t}=1.26$, $p=.210)$ nor the frequency of physical assessment $(\mathrm{t}=$ $0.81, p=.421$ ) did not differ. When the nurses with less than 3 years of clinical experience were compared to those with more than 3 years, there was no statistically significant difference. Nurses with more than 5 years of clinical work experience performed significantly more frequent physical assessment $(\mathrm{t}=-2.49, p=.014)$ than those with less than 5 years. Their training needs was higher than those with less than 5 years of experience $(\mathrm{t}=-2.01$, $p=.047$ ) (Table 5).

\section{The relationship among perceived competen- cy, frequency, and training needs about physical assessment}

The perceived competency was positively related to the frequency of assessment $(\mathrm{r}=.35, p<.001)$, and negatively related to the total training needs but it did not reach the statistical significance $(\mathrm{r}=-.17, p=.091)$.

\section{DISCUSSION}

This study results revealed lack of competency, infrequent use of skills, and training needs in some of the core assessment silks. It also corresponds with previous studies which reported close relationship between confidence and frequency of physical assessment. Regarding competency and frequency, 'auscultate lung sounds', and 'auscultate heart sounds' were identified as one of the five least competent skills. Low level of competency in auscultating lung and heart corresponded with low frequency of performing these skills. This result is similar to the findings of previous study in which the lack of confidence was the most frequently reported barrier of performing physical assessment (Reaby, 1990). This result suggests that auscultation of heart and lung has not yet incorporated to the part of routine practice among registered nurses in Korea. It is of note that in the survey of

Table 4. Perceived Competency, Frequency, and Training Needs by the Assessment Methods

$(N=104)$

\begin{tabular}{|c|c|c|c|}
\hline \multirow{2}{*}{ Assessment methods } & Perceived competency & Frequency & Training needs \\
\hline & $\mathrm{M} \pm \mathrm{SD}$ & $\mathrm{M} \pm \mathrm{SD}$ & $\mathrm{M} \pm \mathrm{SD}$ \\
\hline Inspection $(1,4,6,8,11,13,14,15,19,23,25,29,30)$ & $3.00 \pm 0.45$ & $3.44 \pm 0.74$ & $3.12 \pm 0.67$ \\
\hline Auscultation $(9,10,12)$ & $2.54 \pm 0.61$ & $2.81 \pm 0.98$ & $3.51 \pm 0.62$ \\
\hline Palpation $(4,5,6,7,17,21)$ & $3.26 \pm 0.41$ & $3.85 \pm 0.73$ & $3.12 \pm 0.73$ \\
\hline Multi-methods (2, 3, 16, 18, 20, 22, 24, 26, 27, 28) & $3.28 \pm 0.44$ & $3.93 \pm 0.60$ & $3.12 \pm 0.70$ \\
\hline
\end{tabular}


Table 5. Comparison of Perceived Competency, Frequency of Performing, and Training Needs about Physical Assessment by the Demographic Characteristics

\begin{tabular}{|c|c|c|c|c|c|c|c|}
\hline \multirow{2}{*}{ Characteristics } & \multirow{2}{*}{ Categories } & \multicolumn{2}{|c|}{ Perceived competency } & \multicolumn{2}{|c|}{ Frequency } & \multicolumn{2}{|c|}{ Training needs } \\
\hline & & $\mathrm{M} \pm \mathrm{SD}$ & $\mathrm{t}(p)$ & $\mathrm{M} \pm \mathrm{SD}$ & $t(p)$ & $\mathrm{M} \pm \mathrm{SD}$ & $\mathrm{t}(p)$ \\
\hline \multirow{2}{*}{$\begin{array}{l}\text { Educational } \\
\text { preparation }\end{array}$} & 3 years & $93.26 \pm 12.11$ & \multirow[t]{2}{*}{$1.35(.181)$} & $108.56 \pm 20.18$ & \multirow[t]{2}{*}{$0.33(.745)$} & $94.09 \pm 20.34$ & \multirow[t]{2}{*}{$-0.74(.463)$} \\
\hline & 4 years & $88.82 \pm 13.79$ & & $106.88 \pm 20.33$ & & $97.88 \pm 12,83$ & \\
\hline \multirow{6}{*}{$\begin{array}{l}\text { Work } \\
\text { experience }\end{array}$} & $<1$ year & $89.42 \pm 11.51$ & \multirow[t]{2}{*}{$-1.26(.210)$} & $105.11 \pm 15.88$ & \multirow[t]{2}{*}{$-0.81(.421)$} & $102.57 \pm 13.38$ & \multirow[t]{2}{*}{$2.01(.047)$} \\
\hline & $\geq 1$ year & $93.36 \pm 12.49$ & & $109.04 \pm 19.79$ & & $92.97 \pm 19.80$ & \\
\hline & $<3$ years & $91.50 \pm 11.42$ & \multirow[t]{2}{*}{$-0.84(.403)$} & $107,83 \pm 16.48$ & \multirow[t]{2}{*}{$-0.24(.812)$} & $92.67 \pm 19.77$ & \multirow[t]{2}{*}{$-0.98(.331)$} \\
\hline & $\geq 3$ years & $93.55 \pm 13.09$ & & $108.71 \pm 21.10$ & & $96.36 \pm 18.56$ & \\
\hline & $<5$ years & $92.11 \pm 11.47$ & \multirow[t]{2}{*}{$-0.56(.579)$} & $104.71 \pm 17.85$ & \multirow[t]{2}{*}{$-2.49(.014)$} & $91.80 \pm 19.26$ & \multirow[t]{2}{*}{$-2.01(.047)$} \\
\hline & $\geq 5$ years & $93.50 \pm 13.77$ & & $114.08 \pm 19.88$ & & $99.42 \pm 18.10$ & \\
\hline
\end{tabular}

nursing students in the United States, cardiovascular and respiratory assessments were the two most important and frequently performed skills (Barbarito, Carney, \& Lynch, 1997). In one study, cardiovascular or respiratory assessment such as auscultate precordial landmarks, apical pulse, heart rhythm, rate and murmurs and breathing sounds were reported as daily or weekly utilized skills among registered nurses in the United States (Secrest, Norwood, \& DuMont, 2005). Another study identified cardiovascular and respiratory assessment comprised of one third of core physical examination skills (Giddens, 2007). These three studies reflect different clinical nursing practice pattern of registered nurses. In western countries, strong emphasis has been placed on cardiovascular and respiratory auscultation as routine practice.

It is of question what hinders Korean nurses to become competent in auscultation skill. Is it because of the culture where auscultation using stethoscope is considered as a more of the physicians' role? Is it because of educational approach where student nurses have less opportunity to get exposed to auscultation in clinical practicum? As addressed in previous study by Lont (1992), the low competency of auscultation might result from infrequent performance among nurses especially whose practice setting and expected roles are different. Despite registered nurses in Korea were encouraged to perform physical assessment on regular basis, performed assessments were often limited to inspection and the auscultation of lung and heart were rarely utilized except in special care units (Shin et al., 2009). It is considered that the roles of nurses in Korea are still evolving and not yet fully expanded in performing physical assessment. Further studies are warranted about the factors contributing low competency and infrequent use of auscultation skill in physical assessment. Nurses rated 'palpate distal pulses for circulation' as the most competent skill. This reflects current nursing practice in Korea, where distal pulses are routinely checked by nurses without machinery monitoring support.

Contrast to heart and lung sound auscultation, 'Auscultate abdomen for bowel sounds' was one of less competent area while the frequency of performing this skill rated as the third. The accuracy of the assessment become questionable as nurses used the skill in clinical practice with low competency. Their concern about competency was reflected in their training needs as the nurses rated 'Auscultate abdomen for bowel sounds' the second highest among 30 core physical assessment skills.

Among body systems, assessment in neurology system was the most competent and frequently performed area whereas respiratory system being the least competent and the most needed for further training. It is of note that participants were well prepared in the assessment of neurological systems. The perceived competency about cardiovascular system was moderate even though auscultation of heart sound was one of the least competent and least frequently performed physical assessment skills. This could be from other combined cardiovascular assessment skills such as 'palpations of pulses and temperature' which is already in part of routine practice among nurses.

In the analysis of training needs by nurses' characteristics (i.e., work experiences), the result of this study showed that newly graduated nurses required further training for physical assessment even after completion of undergraduate training. Likewise, nurses who had more than 5 years of clinical experience also expressed strong needs for further training. Additional training can improve physical assessment skills (Brown, Brown, \& Bayer, 1987). The participants expressed needs for training for all 30 core physical assessment skills. Training needs for auscultating heart, lung, and bowel sounds were rated 
high among 30 skills. The results indicate that physical assessment is the pertinent subject for continuing education and further training need to be given during the first year of practice and after 5 years of clinical work as a booster. Educational emphasis need to be placed on the physical assessment skills which were rated as less competent, less performed and high in training need when planning training courses for registered nurses.

Of the relationships among study variables, perceived competency in physical assessment was positively associated to the frequency of assessment in this study. Lack of confidence was the most frequently reported barrier of performing physical assessment (Reaby, 1990). It is difficult to determine whether competency influenced the frequency of assessment, vice versa or reciprocal in nature. Thus it needs further investigation as there has been lack of studies which investigated the relationship between perceived competency and the frequency of performance. Self-confidence, effective educational preparation, accepting physical assessment as a part of nursing responsibility and support from other disciplines were the factors which influenced the performance of physical assessment among nurse practitioners (Colwell \& Smith, 1985; McElhinney, 2010). Factors that might have influenced the competency and frequency of perormance need further investigation.

Edmunds, Ward and Barnes (2010) pointed that the use of assessment skill is not only the matter of educational preparations but the professionalism that individual nurses have. In their study, nurses with broader and clearer views of nursing utilized more assessment skills. Incorporating aforementioned strategies preparing nurses for physical assessment and support of professionalism would be the key to improve competency in physical assessment among registered nurses.

There are limitations in this study. The participants of this study were recruited from convenience sampling procedure which limits the generalization of the study results. Factors that might have contributed to the level of competency and the frequency were not fully assessed thus he interpretation of the study results is limited to the study variables. Further study is warranted including the analysis of major variables by other key factors in relation to characteristics of nurses such as practice area.

\section{CONCLUSION}

This study evaluated perceived competency in physical assessment among registered nurses in Korea where nursing roles are still evolving. The perceived competency, frequency of physical assessment varied by assessment skills whereas further training was requested for all 30 core physical assessment skills. More emphasis need to be placed on the physical assessment skills with low competency, low frequency of physical assessment and high training needs such as 'Auscultating lung sounds' and 'Auscultating heart sounds.' Educational effort for training both newly graduated and experienced nurses would contribute to secure the quality of patient's care and to accelerate nurses' skilled physical assessment.

\section{REFERENCES}

American Association of Colleges of Nursing (AACN).(2008). The essentials of baccalaureate education for professional nursing practice. AACN, Washington, DC. Retrieved April 12, 2011 from http://www.aacn.nche.edu/education/pdf/bacce ssentials08.pdf.

Barbarito, C., Carney, L., \& Lynch, A. (1997). Refining a physical assessment course. Nurse Education, 22(3), 6.

Brown, M. C., Brown, J. D., \& Bayer, M. M. (1987). Changing nursing practice through continuing education in physical assessment: perceived barriers to implementation. Journal of Continuing Education in Nursing, 18(4), 111-115.

Colwell, C. B., \& Smith, J. (1985). Determining the use of physical assessment skills in the clinical setting. Journal of Nursing Education, 24(8), 333-339.

Edmunds, L., Ward, S., \& Barnes, R. (2010). The use of advanced physical assessment skills by cardiac nurses. British Journal of Nursing, 19(5), 282-287.

Faul, F., Erdfelder, E., Lang, A. G., \& Buchner, A. (2007). G*Power 3: A flexible statistical power analysis program for the social, behavioral, and biomedical sciences. Behavior Research Methods, 39(2), 175-191.

Giddens, J. F. (2007). A survey of physical assessment skills performed by RNs: lessons for nursing education. Journal of Nursing Education, 46(2), 83-87.

Giddens, J. F., \& Eddy, L. (2009). A survey of physical examination skills taught in undergraduate nursing programs: are we teaching too much? Journal of Nursing Education, 48 (1), 24-29.

Gilje, F. L., Klose, P. M., \& Birger, C. J. (2007). Critical clinical competencies in undergraduate psychiatric-mental health nursing. Journal of Nursing Education, 46(11), 522-526.

International Council of Nurses. (2003). ICN Framework of Competencies for the generalist Nurse. International Council of Nurses, Geneva.

Institute of Medicine (IOM). (2003). Health professions education: A bridge to quality. Washington DC: National Academies Press. 
Kim, M. (2006). [Development of objectives in nursing clinical education based on the Nursing Core Competencies]. Taehan Kanho Hakhoe Chi, 36(2), 389-402. http://dx.doi.org/2006 04389 [pii]

Lont, K. L. (1992). Physical assessment by nurses: A study of nurses' use of chest auscultation as an indicator of their assessment practices. Contempory Nurse, 1(2), 93-97.

McElhinney, E. (2010). Factors which influence nurse practitioners ability to carry out physical examination skills in the clinical area after a degree level module-an electronic Delphi study. Journal of Clinical Nursing, 19(21-22), 3177-3187. http://dx.doi.org/10.1111/j.1365-2702.2010.03304.x

Minick, P. (1995). The power of human caring: Early recognition of patient problems. Scholarly Inquiry for Nursing Practice, 9(4), 303-317; discussion 319-321.

Minick, P., \& Harvey, S. (2003). The early recognition of patient problems among medical-surgical nurses. Medsurg Nursing, 12(5), 291-297.

Oh, P. J., Kim, I. O., Shin, S. R., \& Jung, H. K. (2004). [Development of Web-based multimedia content for a physical ex- amination and health assessment course]. Taehan Kanho Hakhoe Chi, 34(6), 994-1003. http://dx.doi.org/200410994 [pii]

Reaby, L. L. (1990). The effectiveness of an education program to teach Australian nurses comprehensive physical assessment skills. Nurse Education Today, 10(3), 206-214.

Secrest, J. A., Norwood, B. R., \& duMont, P. M. (2005). Physical assessment skills: A descriptive study of what is taught and what is practiced. Journal of Professional Nursing, 21(2), 114-118. http://dx.doi.org/S8755722305000189 [pii]

Shin, H., Kim, B. J., \& Kang, H. S. (2009). [Use of physical assessment skills and education needss of advanced practice nurses and nurse specialists]. Journal of Korean Academy of Nursing, 39(5), 709-719. http://dx.doi.org/200910709pii] 10. [4040/jkan.2009.39.5.709

Zambas, S. I. (2010). Purpose of the Systematic Physical Assessment in Everyday Practice: Critique of a "Sacred Cow". Journal of Nurse Education, 1-6. http://dx.doi.org/10.3928/014 84824-20100224-03 